\title{
ORIGINAL ARTICLE Body image dissatisfaction and its relationship with physical activity and body mass index in Brazilian adolescents
}

\author{
Insatisfação com a imagem corporal e sua relação com atividade \\ física e índice de massa corporal em adolescentes brasileiros \\ Maria F. Laus', Telma M. Braga Costa², Sebastião S. Almeida'
}

\begin{abstract}
Objective: To evaluate body image dissatisfaction and its relationship with physical activity and body mass index in a Brazilian sample of adolescents. Methods: A total of 275 adolescents (139 boys and 136 girls) between the ages of 14 and 18 years completed measures of body image dissatisfaction through the Contour Drawing Scale and current physical activity by the International Physical Activity Questionnaire. Weight and height were also measured for subsequent calculation of body mass index. Results: Boys and girls differed significantly regarding body image dissatisfaction, with girls reporting higher levels of dissatisfaction. Underweight and eutrophic boys preferred to be heavier, while those overweight preferred be thinner and, in contrast, girls desired to be thinner even when they are of normal weight. Conclusion: Body image dissatisfaction was strictly related to body mass index, but not to physical activity.
\end{abstract}

\section{RESUMO}

Objetivo: Investigar a insatisfação com a imagem corporal e sua relação com atividade física e índice de massa corporal em adolescentes brasileiros. Métodos: Participaram do estudo 275 adolescentes (139 meninos e 136 meninas) com idade entre 14 e 18 anos. A coleta de dados consistiu na tomada de medidas de peso e altura, seguida pela aplicação da Escala de Figuras de Silhuetas e do Questionário Internacional de Atividade Física. Resultados: As meninas apresentaram índices significativamente maiores de insatisfação com a imagem corporal. Meninos eutróficos e com baixo peso relataram o desejo de pesar mais, enquanto meninos acima do peso gostariam de pesar menos. Em contrapartida, as meninas desejam ser mais magras, mesmo quando estão com peso normal. Conclusão: A insatisfação com a imagem corporal foi estritamente relacionada ao índice de massa corporal, mas não manteve relação com a prática de atividade física.

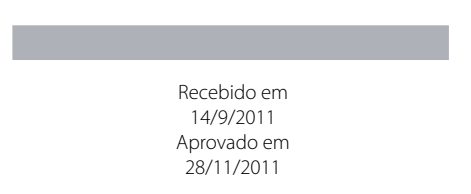
$28 / 11 / 2011$

Universidade de São Paulo (USP), Faculdade de Filosofia, Ciências e Letras de Ribeirão Preto, Departamento de Psicologia 2 Universidade de Ribeirão Preto (UNAERP), Curso de Nutrição.

Address for correspondence: Sebastião S. Almeida Laboratório de Nutrição e Comportamento, Departamento de Psicologia, Faculdade de Filosofia, Ciências e Letras de Ribeirão Preto, Universidade de São Paulo

Av. Bandeirantes, 3900 - 14040-901 - Ribeirão Preto, SP, Brasil

Tel.: (16) 3602-3663

E-mail: sebasalm@usp.br

\section{Palavras-chave \\ Imagem corporal, atividade física, índice de massa corporal, adolescentes. \\ Keywords
Body image, physical activity, body mass index,}




\section{INTRODUCTION}

Body image has been considered an internal representation of an individual's body shape, weight, size, or other features related to physical appearance'. However, researchers have long argued that body image has a multifactorial etiology involving perceptual, affective, cognitive, evaluative, and investment/behavioral components ${ }^{2}$.

Because adolescence is a period characterized by great emotional, social, and physical change, body image disturbance is among the most widespread disorders associated with the onset of adolescence ${ }^{3}$. Although the research on body image has primarily focused on women and patients with eating disorders ${ }^{4}$, increasing recognition of the psychosocial problems associated with body disturbance among adolescents has led to the need to understand the factors influencing body image for boys and girls in nonclinical populations.

According to some authors, a number of studies have emphasized the problems of distorted body image, dissatisfaction with one's body weight and symptoms of unhealthy weight control among adolescents as a social pressure ${ }^{5}$. The beauty ideal is conveyed and reinforced by many social influences, including media representations, cultural traditions and attitudes of friends and relatives ${ }^{6}$.

Studies conducted in the West during the last three decades reflect general agreement that "ideal body" is equated with youth, beauty, health, competence, and self-control and is a key to many social benefits? ${ }^{7}$. The male ideal is a $V$-shaped figure with emphasis placed on large biceps, chest, and shoulders; whereas the female ideal is to be extremely thin, with emphasis placed on slim hips, bottom, and thighs ${ }^{8}$. However, since for most people this ideal is impossible to achieve, body image disturbance is a likely consequence.

It is known that body mass index (BMI) has been the most consistent biological characteristic related to body image satisfaction ${ }^{9}$ with some studies finding that BMI explained unique variance in body dissatisfaction above and beyond socio-cultural variables ${ }^{10}$. The general finding from cross-sectional and longitudinal research has been that girls and boys who have greater body mass have expressed heightened body image disturbances?.

A substantial body of literature data attests to the negative distress caused by body image disturbance in both females and males, as well as its association with depression symptoms, low self-esteem, and increased risk for suicide ${ }^{3,11}$. It is also known that body image disturbances might be associated with unhealthy weight-control behaviors ${ }^{10}$.

In that way, physical activity is often considered as a way to reduce body weight and research shows that adolescents frequently relate fitness to appearance and to "looking good"12. Thus, according to Jankauskiené and Kardelis ${ }^{5}$, several studies have revealed many problems related to weight, body image and physical activity such as pathologi- cal weight control concerns, drive for thinness (particularly in girls), drive for muscularity (particularly in boys), and commitment to exercise.

On the other hand, some authors argue that regular physical activity among children and adolescents could be associated with high self-esteem, positive social skills, and a reduced risk of participating in health-risk behaviors ${ }^{13}$ in which adolescents often engage, with immediate or longterm consequences to their health and well-being.

On this basis, adolescents' body concerns are an important issue and studies should be conducted in an attempt to answer a number of different questions related to body image disorders. Although this is an important issue, only a few published studies explore issues surrounding body image perception and its related factors among Brazilian adolescents. Thus, the main purpose of the present study was to evaluate body image dissatisfaction and its relationship with physical activity and body mass index in a Brazilian sample of adolescents.

\section{METHODS}

\section{Participants}

Before the beginning of the study, a survey was conducted in the Municipal Secretary of Education to verify the number of adolescents regularly enrolled in high school in the city, resulting in 23.754 students. After that, a simple random and convenient sample corresponding to, at least, $1 \%$ of this total was defined. To ensure the inclusion of subjects from all socioeconomic strata, five public and five private schools were randomly selected from each region of the city (north, south, west, east and central). The authors made contact to each director and, after the agreement, students were randomly recruited to voluntarily participate in the study. At the end, 275 adolescents (139 boys and 136 girls) agreed to participate in the study and there were no refusals during data collection. Participants ranged in age from 14 to 18 years $(16.2 \pm 1.0)$.

\section{Measures}

Body Mass Index (BMI): BMI is defined as the ratio of weight $(\mathrm{kg})$ to height $(\mathrm{m})$ squared. Weight was measured using a calibrated electronic scale (Kratos-Cas, Brazil) and subjects were weighed wearing light clothes, barefoot and carrying no heavy objects. Height was measured using a portable anthropometer (Kratos-Cas, Brazil) set against the wall, ensuring accurate subject posture before reading the fixed marker. Nutritional status was defined by the age- and sex-specific percentile of BMI based on Ministry of Health parameters ${ }^{14}$. Weight and height data were processed with the Epi-Info ${ }^{\oplus}$ software, which classified each individual according to the percentile limits as follows: underweight $P<3$; normal weight $P 3-P<85$; overweight $\geq P 85-P<97$, and obesity $P \geq 97$. 
International Physical Activity Questionnaire (IPAQ): The IPAQ was developed as an instrument for crossnational monitoring of physical activity and inactivity ${ }^{15}$. The Brazilian version of the questionnaire was validated for adolescents of both sexes by Guedes et al. ${ }^{16}$.

The short version of the IPAQ assesses physical activity undertaken across a comprehensive set of domains including: leisure time physical activity; domestic and gardening (yard) activities, work-related physical activity, and transport-related physical activity, and asks about three specific types of activity undertaken in the above four domains. The specific types of activity assessed are walking, moderate-intensity activities and vigorous-intensity activities. The 3 items in the short IPAQ form were structured to provide separate scores on walking, moderate-intensity and vigorous-intensity activity. Computation of the total score for the short form requires summation of the duration (in minutes) and frequency (days) of walking and of moderate-intensity and vigorousintensity activities. For each question, participants are given examples of moderate, vigorous, and walking activities and physiological cues for breathing and heart rate to help them recall activities at an appropriate intensity level. The IPAQ does not take into account activities performed for less than 10 consecutive minutes, and the intensity is based on selfreport ${ }^{15}$. Data are analyzed as categorical variable.

The Contour Drawing Scale (CDS): The Brazilian version of the scale was created and validated by Kakeshita et al. ${ }^{17}$. In this study it was used the adult scale, which was tested by the authors in adolescents*. The scale comprises a set of fifteen contour drawings of each gender presented on separate cards showing escalating measures, from leaner to wider drawings, and mean BMl ranging from 12.5 to $47.5 \mathrm{~kg} / \mathrm{m}^{2}$, which evaluates body image dissatisfaction. The method applied consisted of asking subjects to pick one card from a set of cards displayed in ascending order, which would better describe their own body contour at that time ("Perceived" BMI). Subjects were then asked to point out the card with their desired body contour ("Ideal" BMI) and the card which indicates a healthy BMI. Body dissatisfaction is represented as the discrepancy between perceived and ideal BMI. Results are given as a continuous variable, and the closer to zero, the lower dissatisfaction.

\section{Procedure}

The project was approved by the Institutional Ethics Committee. Data collection was carried out in rooms provided by the schools and comprised the application of contour drawing tests, weight and height measures and self-administration of the IPAQ. All data were collected in 2008 by one investigator

\footnotetext{
* Laus MF, Murarole, MB, Braga Costa TM, Almeida SS. Estudo de fidedignidade teste-reteste de uma escala de silhuetas brasileira em adolescentes (unpublished manuscript).
}

trained in the use of the instruments. Written informed consent was obtained from all subjects.

\section{Data analysis}

Data were analyzed using evaluation scales of each test and the calculation of BMI. Statistical analysis was performed using the Statistica 5.0 software. Data adhered to the assumption for parametric data. Analysis of Variance (ANOVA) was used to determine whether there were any differences in BMI, level of physical activity and body image dissatisfaction between boys and girls and possible interactions between these factors. When applicable, the multiple comparisons NewmanKeuls test was used to determine which groups were different. A Pearson correlation test between BMI and CDS was also performed. The level of significance was set at $5 \%$.

\section{RESULTS}

Table 1 describes the characteristics of the sample in terms of physical activity level, nutritional status, BMI, body image perception, and dissatisfaction. As can be seen, approximately $73.4 \%$ of the boys and $54.4 \%$ of the girls were participating in moderate-intensity physical activity lasting for at least $10 \mathrm{~min}$. Seventy-eight percent of the boys and $83.1 \%$ of the girls were of normal weight and there was no significant difference in mean BMI between adolescent boys and girls $(p<.05)$.

Table 1. Descriptive statistics of the study sample $(n=275)$

\begin{tabular}{lcc}
\hline & $\begin{array}{c}\text { Boys } \\
(\mathbf{n}=139)\end{array}$ & $\begin{array}{c}\text { Girls } \\
(\mathbf{n}=136)\end{array}$ \\
\hline $\begin{array}{l}\text { Physical activity level } \\
\text { Sedentary }\end{array}$ & & \\
Low activity & 2.9 & 6.8 \\
Moderate activity & 23.7 & 39.0 \\
High activity & 47.5 & 41.2 \\
Nutritional status & 25.9 & 13.2 \\
Underweight & & \\
Normal weight & 3.6 & 0.7 \\
Risk of overweight & 78.4 & 83.1 \\
Overweight & 10.1 & 12.5 \\
Body mass index & 7.9 & 3.7 \\
CDS $^{\ddagger}$ & $22.0(3.8)(16.0-35.6)$ & $21.7(3.5)(16.9-35.6)$ \\
"Perceived" BMI & & \\
"Ideal" BMI & $24.4(6.2)$ & $26.7(6.2)$ \\
"Health" BMI & $24.2(3.5)$ & $24.2(3.6)$ \\
Dissatisfaction" & $24.8(3.6)$ & $24.9(3.5)$ \\
\hline & $-0.2(5.5)$ & $-2.5(5.6)^{\mathrm{a}}$
\end{tabular}

${ }^{\dagger}$ Data are reported in percentage. ${ }^{\ddagger}$ Data are reported in $\mathrm{kg} / \mathrm{m}^{2}$ as mean (Standard Deviation). ${ }^{\mathrm{a}} \mathrm{p}<.001$ compared to boys. 
Still on table 1, it can be seen that, according to the CDS, girls would like to have a lower BMI than they think they have. Body image data were then submitted to one-way (dissatisfaction $x$ gender) ANOVA to determine possible differences in dissatisfaction between boys and girls. Table 1 shows that boys and girls differed significantly in body dissatisfaction $\left.\left[F_{(1,273)}=11,26 ; p<.001\right)\right]$, with girls reporting higher levels of dissatisfaction than boys.

In order to evaluate differences in body image dissatisfaction between boys and girls who currently do and do not participate in some form of physical activity, a two-way ANOVA was performed. As can be seen, ANOVA revealed no significant effect of the body image dissatisfaction $x$ physical activity levels $x$ gender interaction $(p>.05)$ which indicates that, in this sample, dissatisfaction exist regardless physical activity level or gender (Table 2).

Table 2. Means (and Standard Deviations) for body image dissatisfaction (in $\mathrm{kg} / \mathrm{m}^{2}$ ) of boys and girls according to physical activity level and nutritional status

\begin{tabular}{lcc}
\hline & \multicolumn{2}{c}{ Body image dissatisfaction } \\
\cline { 2 - 3 } & $\begin{array}{c}\text { Boys } \\
(\mathbf{n}=139)\end{array}$ & $\begin{array}{c}\text { Girls } \\
(\mathbf{n}=136)\end{array}$ \\
\hline Physical activity level & & \\
Sedentary & $-6.3(1.6)$ & $-1.9(1.9)$ \\
Low activity & $-0.8(1.2)$ & $-1.8(0.7)$ \\
Moderate activity & $0.0(0.7)$ & $-3.2(0.8)$ \\
High activity & $0.6(0.7)$ & $-2.2(0.8)$ \\
Nutritional status & & \\
Underweight & $6.0(1.3)^{\mathrm{a}}$ & $0.0(0.0)^{\mathrm{a}}$ \\
Normal weight & $1.2(1.3)^{\mathrm{a}}$ & $-1.5(0.5)^{\mathrm{a}}$ \\
Risk of overweight & $-4.5(1.1)^{\mathrm{b}}$ & $-7.4(1.3)^{\mathrm{b}}$ \\
Overweight & $-11.4(1.8)^{\mathrm{b}}$ & $-8.5(1.0)^{\mathrm{b}}$ \\
\hline $\mathrm{a}, \mathrm{p} \mathrm{p}<.05$ (means with different superscripts differ significantly).
\end{tabular}

A two-way ANOVA also was conducted to determine differences in body image dissatisfaction between boys and girls according to the nutritional status. As can be seen on table 2, ANOVA demonstrated no significant effect of gender $(p>.05)$ but revealed a significant effect of the dissatisfaction $x$ nutritional status interaction $\left[\mathrm{F}_{(3.267)}=31.71 ; \mathrm{p}<.05\right]$. Posthoc analysis showed that respondents with higher BMI were more dissatisfied with their weight than respondents with lower BMI. As expected, underweight and normal weight boys would like to be heavier, while those overweight would like to be thinner. In contrast, girls would like to be thinner, even when they are normal weight.

Significant correlations were observed between body image dissatisfaction and BMI in boys $(r=-.79)$ and girls $(r=$ $-.60)$, indicating that, in this sample, dissatisfaction with body image proportionally increased with increasing BMI in both sexes $(p<.05)$ (Table 3$)$.
Table 3. Pearson's correlation coefficients between body mass index $\left(\mathrm{kg} / \mathrm{m}^{2}\right)$ and body image dissatisfaction $\left(\mathrm{kg} / \mathrm{m}^{2}\right)$ for boys and girls

\begin{tabular}{llc}
\hline & \multicolumn{2}{c}{ Body image dissatisfaction } \\
\cline { 2 - 3 } & Boys & Girls \\
\hline Body mass index & $-.79^{\mathrm{a}}$ & $-.60^{\mathrm{a}}$ \\
\hline
\end{tabular}

a Significant at $p<.05$

\section{DISCUSSION}

The objective of the present study was to investigate body image dissatisfaction and its relationship with physical activity and body mass index in a Brazilian sample of adolescents. The results showed a large proportion of adolescents engaged in some form of physical activity and that most participants were of normal weight. Body image dissatisfaction was strictly related to BMI, but not to physical activity.

Our data concerning the levels of physical activity of adolescents tested by the IPAQ agree with other national studies $^{18}$. Thus, it is important to note that there is a difference between "physical activity" and "exercise". Caspersen et al. ${ }^{19}$ define physical activity as any bodily movement produced by skeletal muscles that results in energy expenditure. In daily life it can be categorized into occupational, sports, conditioning, household, or other activities. On the other hand, exercise is a subcategory of physical activity. In fact, both have a number of common elements; however, exercise is not synonymous with physical activity. Exercise is physical activity that is planned, structured, repetitive, and intentional, in the sense that improvement or maintenance of one or more components of physical fitness is an objective ${ }^{19}$. The IPAQ is a measure of total physical activity and includes transportation and occupational physical activities making no distinction between the two terms.

Particularly in developing countries, occupational and transportation activities represent a substantial proportion of total physical activity ${ }^{20}$. Thus, most of the participants possibly practice this kind of activity, and not specifically "exercise". Since it is known that exercise is more often performed for appearance-related reasons ${ }^{21}$ compared to physical activities, this could be one explanation for the lacking relationship between physical activity and body image disturbance.

Concerning nutritional status, Madrigal et al.22 have pointed out that the relationship between body weight and body image self-perception is well-documented in the literature, as confirmed in the present study. The present study shows that body dissatisfaction scores of both boys and girls were significantly correlated with their BMI, indicating that body image disturbance increases with increasing BMI. Similarly, previous studies have also found a direct relationship between $\mathrm{BMI}$ and body image disturbance ${ }^{23,24}$. A review conducted by Wardle ${ }^{25}$ examining recent empirical evidence 
on the relationship between obesity and body dissatisfaction found, without exception, greater body dissatisfaction among heavier children and adolescents, confirming that overweight during adolescence may indicate greater body concern and discomfort.

The high correlation between body image and anthropometric characteristics suggests that the analysis of body image perception could play an important role in nutritional surveillance ${ }^{24}$.

According to Champion and Furnham ${ }^{26}$, many theorists have postulated that the media may play a central role in creating and exacerbating the phenomenon of body dissatisfaction. Television and other media represent one of the most important and underrecognized influences on children and adolescents' behavior ${ }^{27}$. Figures in the media provide information on fashion, beauty, and body satisfaction, and have the potential to provide positive images for adolescents in the process of their social development and emerging sense of identity. However, adolescents often identify with media characters who are unnaturally thin or who engage in harmful behaviors, and often develop unrealistic and unhealthy norms of physical appearance ${ }^{28}$.

The adult stereotypes of beauty and obesity are naturally assimilated by children and a review conducted by Feldman et al..$^{29}$ investigating the absorption of these stereotypes in children concluded that children by the age of 6-9 years old already acquire an active dislike of the obese body and by the age of 7 years have assimilated adult cultural perceptions of attractiveness ${ }^{26}$.

According to Pesa et al. ${ }^{30}$, adolescence is a period of life marked by pronounced physical, psychological, emotional, and social changes. The physical changes that characterize this life stage have been implicated as a trigger for body image problems in both males and females. With pubertal development, girls experience an increase in body fat ${ }^{31}$. This new body often conflicts with the cultural ideal of a slender body and girls generally become more dissatisfied with their bodies. It stands to reason that excess body weight may have a negative impact on the well-being especially of female adolescents $^{31}$. In fact, dissatisfaction with body image in girls is normally shown by the desire to lose weight. In contrast, studies have shown that boys seem to be approximately equally divided between those desiring weight gain and those desiring weight loss ${ }^{8}$, as confirmed in the present study.

This study has presented numerous interesting findings. Nevertheless, it is not without limitations. This study has presented numerous interesting findings. Nevertheless, it is not without limitations. The first one is related to the use of one self-applicable instrument, which may contain a bias component, once it depend on those who will answer the questions, fact that can result in subjective data. Second, there is the relatively small sample size, which could not properly represent all considered strata, but may provide baseline data to begin to examine body dissatisfaction and its related factors during adolescence.

In conclusion, boys and girls differed significantly in body dissatisfaction, with girls reporting higher levels of dissatisfaction. In general, underweight and normal weight boys would like to be heavier, while those overweight would like to be thinner and, in contrast, girls would like to be thinner, even when they are of normal weight. Contrary to expectations, body image dissatisfaction was strictly related to BMI, but not to physical activity.

These results demonstrated that biological factors, as $\mathrm{BMI}$, may play an important role in the development and maintenance of body image dissatisfaction and provided helpful information about risk population that should be target of interventional programs.

\section{ACKNOWLEDGE}

The authors acknowledge Fundação de Amparo à Pesquisa do Estado de São Paulo - FAPESP for financial support (Process 2006/01606-6).

\section{REFERENCES}

1. Powell MR, Hendricks B. Body schema, gender, and other correlates in nonclinical populations. Genet Soc Gen Psychol Monogr. 1999;125(4):333-412.

2. Smolak L. Body image in children and adolescents: where do we go from here? Body Image. $2004 ; 1(1): 15-28$

3. Brausch AM, Muehlenkamp JJ. Body image and suicidal ideation in adolescents. Body Image. 2007:4(2):207-12.

4. Cash TF, Deagle EA. The nature and extent of body image disturbances in anorexia nervosa: a meta-analysis. Int J Eat Disord. 1997;22(2):107-25.

5. Jankauskiené $R$, Kardelis K. Body image and weight reduction attempts among adolescent girls involved in physical activity. Medicina (Kaunas). 2005;41(9):796-801.

6. Thompson JK, Heinberg LJ. The media's influence on body image disturbance and eating disorders: we've reviled them, now can we rehabilitate them? J Soc Issues. 1999;55(2):339-53.

7. Stice E, Bearman SK. Body image and eating disturbances prospectively predict growth in depressive symptoms in adolescent girls: a growth curve analysis. Dev Psychol. 2001;37(5):597-607.

8. Furnham A, Badmin N, Sneade I. Body image dissatisfaction: gender differences in eating attitudes, self-esteem, and reasons for exercise. J Psychol. 2002;136(6):581-96.

9. Jones DC. Body image among adolescent girls and boys: a longitudinal study. Dev Psychol. 2004:40(5):823-35.

10. Bardone-Cone AM, Cass KM, Ford JA. Examining body dissatisfaction in young men within a biopsychosocial framework. Body Image. 2008;5(2):183-94.

11. Van den Berg P, Paxton JS, Keery H, Wall M, Guo J, Neumark-Sztainer D. Body dissatisfaction and body comparison with media image in males and females. Body Image. 2007;4(3):257-68.

12. Placek JH, Griffin LL, Dodds P, Raymond C, Tremino F, James A. Chapter 3. Middle school students' conceptions of fitness: the long road to a healthy lifestyle. JTPE. 2001;20(4): 314-23.

13. Aaron DJ, Dearwater SR, Anderson R, Olsen T, Kriska AM, Laporte RE. Physical activity and the initiation of high-risk health behaviors in adolescents. Med Sci Sports Exerc. 1995;27(12):1639-45. 
14. Brasil - Ministério da Saúde. Incorporação das curvas de crescimento da Organização Mundial da Saúde de 2006 e 2007 no SISVAN. Disponível em: http://nutricao.saude.gov. br/docs/geral/curvas_oms_2006_2007.pdf. Acesso em: 10 jul. 2011.

15. Craig CL, Marshall AL, Sjöström M, Bauman AE, Booth ML, Ainsworth BE, et al. International Physical Activity Questionnaire: 12-Country reliability and validity. Med Sci Sports Exerc. 2003;35(8):1381-95.

16. Guedes DP, Lopes CC, Guedes JERP. Reprodutibilidade e validade do Questionário Internacional de Atividade Física em adolescentes. Rev Bras Med Esporte. 2005;11(2):151-8.

17. Kakeshita IS, Silva AIP, Zanatta DP, Almeida SS. Construção e fidedignidade teste-reteste de escalas de silhuetas brasileiras para adultos e crianças. Psicol Teor Pesqui. 2009;25(2): 263-70.

18. Guedes DP, Guedes JERP, Barbosa DS, Oliveira JA. Níveis de prática de atividade física habitual em adolescentes. Rev Bras Med Esporte. 2001;7(6):187-99.

19. Caspersen CJ, Powell KE, Christenson GM. Physical activity, exercise, and physical fitness: definitions and distinctions for health-related research. Public Health Rep. 1985;100(2):126-31.

20. Brasil - Ministério da Saúde. Inquérito domiciliar sobre comportamentos de risco e morbidade referida de doenças e agravos não transmissíveis: Brasil, 15 capitais e Distrito Federal 2002-2003. Disponível em: http://www.inca.gov.br/publicacoes/publicacao_inquerit022_06.pdf. Acesso em: 10 jul. 2011

21. Strelan P, Mehaffey SJ, Tiggemann M. Self-objectification and esteem in young women: the mediating role of reasons for exercise. Sex Roles. 2003;48(1-2):89-95.
22. Madrigal H, Sanchez-Villegas A, Martinez-González MA, Kearney J, Gibney MJ, Irala J, et al. Underestimation of body mass index through perceived body image as compared to self-reported body mass index in the European Union. Public Health. 2000;114(6):468-73.

23. Sujoldzic A, De Lucia A. A cross-cultural study of adolescents - BMI, body image and psychological well-being. Coll Antropol. 2007;31(1):123-30.

24. Gualdi-Russo E, Albertini A, Argnani L, Celenza F, Nicolucci M, Toselli S. Weight status and body image perception in Italian children. J Hum Nutr Diet. 2008;21(1):39-45.

25. Wardle J. The impact of obesity on psychological well-being. Best Pract Res Clin Endocrinol Metab. 2005;19(3):421-40.

26. Champion H, Furnham A. The effect of the media on body satisfaction in adolescent girls. Eur Eat Disord Rev. 1999;7(3):213-28.

27. Strasburger VC, Donnerstein E. Children, Adolescents, and the media: issues and solutions. Pediatrics. 1999;103(1):129-39.

28. Taveras EM, Rifas-Shiman SL, Field AE, Frazier AL, Colditz GA, Gillman MW. The influence of wanting to look like media figures on adolescent physical activity. J Adolesc Health. 2004;35(1):41-50.

29. Feldman W, Feldman E, Goodman JT. Culture versus biology: children's attitudes towards thinness and fatness. Pediatrics. 1988;81(2):191-4.

30. Pesa JA, Syre TR, Jones E. Psychosocial differences associated with body weight among female adolescents: the importance of body image. J Adolesc Health. 2000;26(5):330-7.

31. McCabe MP, Ricciardelli LA. A prospective study of extreme weight change behaviors among adolescent boys and girls. J Youth Adolesc. 2006;35(3):402-11. 